\title{
Upward Looking Sonar-based Measurements of Sea Ice and Waves
}

\author{
D.B. Fissel, J.R. Marko, E. Ross and T. Kwan \\ ASL Environmental Sciences Inc. \\ 1986 Mills Road \\ Sidney, B.C. V8L 5Y3 Canada \\ John Egan \\ Public Works and Government Services Canada \\ Gatineau, Quebec Canada
}

\begin{abstract}
With the recent reduction in summertime ice cover in the Arctic Ocean, year-long moored measurement programs require detailed information on sea ice thickness and topography data throughout most of the year, as well as ocean wave measurements during summer periods of major sea-ice retreat. This information is required for basic ice covered ocean studies and, increasingly, for addressing important navigation-, offshore structure design/safety- and climate change-issues. Since the early 1990's, upward looking sonar (ULS) instrumentation have been developed and applied to providing under-ice topography data with high horizontal and vertical spatial resolution. The internal recording ULS instruments, or ice profilers, are typically operated from the seafloor on taut line mooring systems.
\end{abstract}

In the winter of 2007-2008, a new generation of ULS instrumentation was field tested, initially in Northumberland Strait near the Confederation Bridge separating the Canadian provinces of New Brunswick and Prince Edward Island. With typical ping rates of $1 \mathrm{~Hz}$, the enhanced capability of the Ice Profiler provides very high resolution measurements of ice keel drafts and the under-ice topography of sea-ice keel features. The upgrades intrinsic to the ULS instrument feature much expanded data storage capacity (from 69 Mbytes to 1-8 Gigabytes) and 16 bit $A / D$ resolution for ice ranges and other parameters. The offered combination of much increased dynamic range (via the 16 bit $\mathrm{A} / \mathrm{D}$ converter) combined with the greatly expanded data storage capacity enables the instrument to operate at much lower gain levels. This facility allows extraction of information on the strength of the backscattering associated with sea-ice in contrast to the larger amplitude acoustic returns from open water, as well as detection of multiple targets from each regular $1 \mathrm{~Hz}$ ping. The instrument's firmware also provides an ocean wave sampling mode in which a $2 \mathrm{~Hz}$ ping rate is used, typically over 20 minutes once each hour, from which non-directional wave spectra and wave parameters can be derived in post processing of the raw data. The new firmware allows the user to program the instrument to operate in up to 12 different sampling schemes over the course of the full deployment. For a typical Arctic Ocean deployment, this enables the instrument to be programmed to measure ocean waves in late summer and early autumn, then both waves and sea ice in autumn, sea ice in the winter and spring, sea ice and waves in the late spring and early summer.

These features were utilized in the Northumberland Strait deployment, operated from Nov. 2007 to April 2008, to optimally detect the floating ice cover targets of interest, avoiding alternative false or null targets. Results are also presented on the measurement of ocean waves with wave heights of up to $3 \mathrm{~m}$, and the early winter measurement of scattered ice keels in the presence of ocean waves.

\section{INTRODUCTION}

In a previous publication [1], we have described results from 2006-2007 field tests of ASL's IPS5 Ice Profiler, a new version of this upward looking sonar instrument, obtained at the ice research site maintained by Public Works Canada at the Confederation Bridge. The Confederation Bridge connects Prince Edward Island with mainland Canada across the $13 \mathrm{~km}$ width of Northumberland Strait. The main thrust of the earlier report was the description of the new features offered by the IPS5 instrument and their use in enhancing the ice-structure interactions studies carried out at the site by the University of Calgary and, in particular, for clarifying the origins of anomalously deep acoustic targets detected in previous studies [2-5]. The latter features were shown to be associated with ice fragments produced by contact between the moving ice cover and a nearby $(100 \mathrm{~m})$ bridge pier which become turbulently mixed down into the water column where they are detected on the appropriate flooding tidal cycle which moves them over the IPS instrument. It was shown that sensible results on the draft of the ice cover could be recovered by imposing an additional restriction which retains only fully saturated signals to establish range vs. time series data truly representative of the overlying ice cover. The procedure was shown to yield reasonable accurate ice cover range/draft depictions when unsaturated range data points were replaced by interpolations from adjacent saturated data.

In the 2007-2008 season, similar field tests were carried out with the monitoring instrument at effectively the same deployment location and after implementation of further upgrades in instrument parameter settings and capabilities. The latter changes were notable in both the firmware and operating parameters as outlined below. 


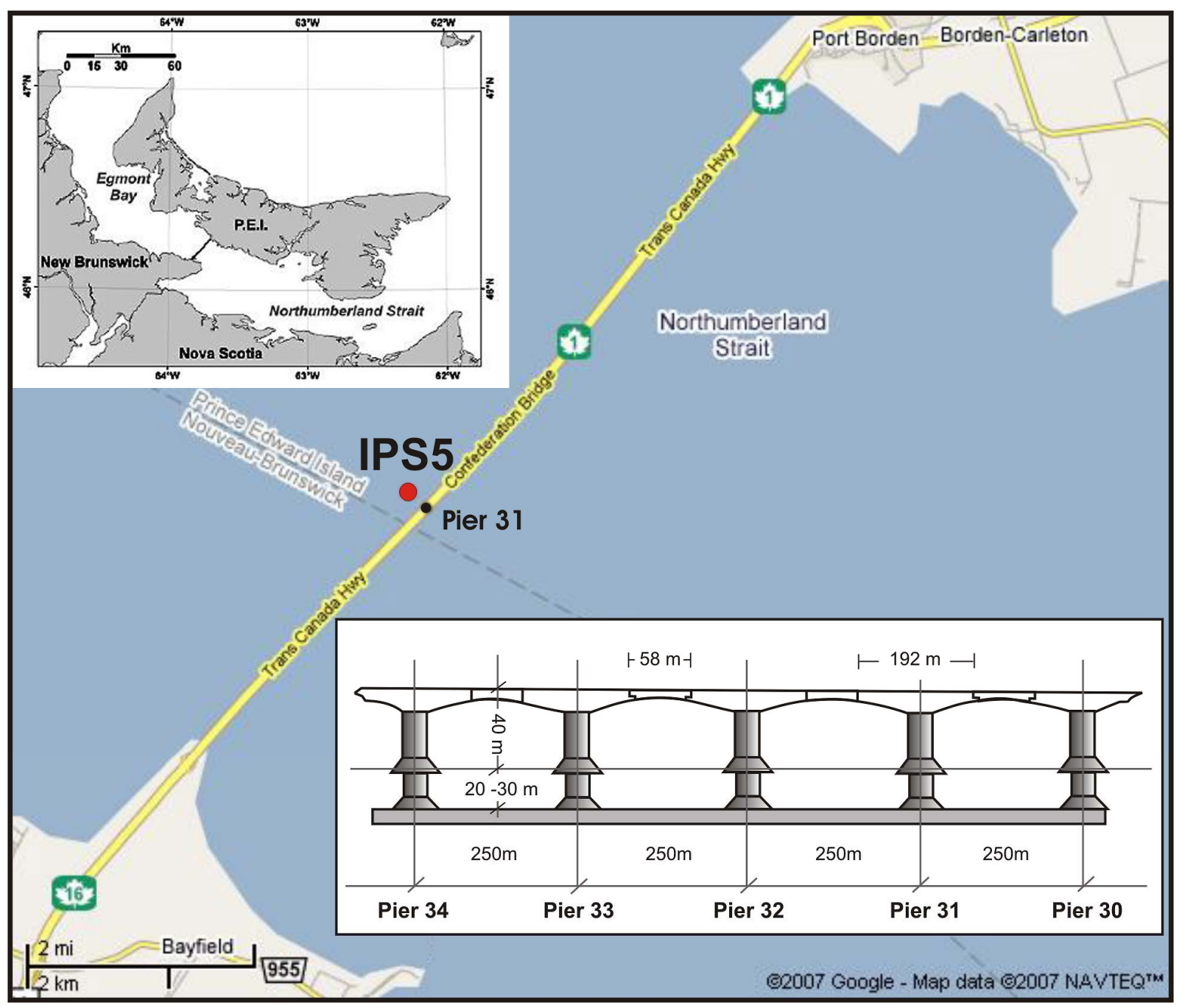

Figure 1. The location of the Ice Profiler (IPS5) near Pier 31 of the Confederation Bridge. Also shown are the location of Northumberland Strait in Eastern Canada and a diagram of the instrumented bridge piers [8] near the IPS5 instrument.

The firmware enhancements were designed to allow operations in up to 12 different sampling schemes over the course of a deployment with users choosing schedules for individual sequences in which data were alternatively collected as: ranges and return amplitudes for up 5 different targets in the water column; full profiles depicting return strength as a function of range and; non-directional wave parameters derived in a wave sampling mode. Gain settings were adjusted to allow full exploitation of the 16 bit resolution of the IPS5's sonar detection system. Previously, the higher sonar power levels detected in the 2006-7 measurements had ruled out easy distinctions between signals scattered from different types of floating ice and open water surfaces and, perhaps, overemphasized the importance of returns from the water column.

Following a brief description of the deployed instrument, this report will present examples of preliminary results obtained in the 2007-8 measurements during two short periods in which conditions were suitable for, alternatively, open water wave studies (December 12-14, 2007 ) and evaluations of ice characterization capabilities in mixed ice and open water conditions (January 29- February 4, 2008).

\section{TEST SITE AND PROGRAM.}

\section{A. Ice Profiler Measurement Location and Operation}

The basic location of the study was, as described in [1], with the sonar instrument located approximately $100 \mathrm{~m}$ off the northwest side of the bridge and connected to it by a nearly perpendicular underwater cable intersecting Pier Shaft 31 on the bridge as shown in Fig. 1. This location for Ice Profiler measurements was chosen to document physical details of the ice as it interacts with the ice shield portion of the heavily instrumented pier shaft. The ice sonar was installed and operated by Public Works and Government Services Canada, (PWGSC) in conjunction with 
Confederation Bridge maintenance and operations staff as part of a joint venture to monitor bridges performance. This sonar data collection is a critical part of the Confederation Bridge Monitoring Project, which studies the ice/bridge structure interactions as well as the effects of other environmental and loading factors by dynamic measurements of accelerations, displacements, stresses and temperatures on instrumented bridge sections. The latter data are analyzed to establish correlations with the ice feature and movement data recorded by ASL's Ice Profiler instrument. The location of the latter instrument is only slightly off the axis of the tidal flows which move toward and away from this pier. Such flows typically have magnitudes of up to $0.9 \mathrm{~m} / \mathrm{s}$ [2-4].

The IPS5 Ice Profiler unit operated at the same $(420 \mathrm{kHz})$ acoustic frequency as a predecessor IPS4 instrument but was distinguished by its: 1- 8 Gigabyte memory storage capacity; 16 bit A/D data resolution; and new firmware which took advantage of these improvements to go beyond mere detection of water or ice interfaces. The latter firmware extension was intended to provide more complete characterizations of returns from or near such surfaces and from within the underlying water columns. During the ice season, the instrument was programmed to detect and store data on up to five separately discernable acoustic targets on each of the ranging pings which were emitted at $1 \mathrm{~s}$ intervals. Additionally, separate profiling pings were generated at $30 \mathrm{~s}$ intervals with subsequent recording of the means of the resulting returns corresponding to each approximately $1 \mathrm{~cm}$ segment of the water column. The unit's low power circuitry is essential for the typically long deployments associated with ice profiling studies, particularly in the Arctic Ocean.

Recent further reductions in power consumption were tested under field conditions. Actual instrument deployment was effected from a small work boat in approximately $20 \mathrm{~m}$ of water with the IPS5 being mounted in an aluminum frame designed to stabilize and maintain the face of the unit's transducer approximately $1.5 \mathrm{~m}$ off the sea floor (Fig. 2).

Focus in the testing was given to verification of general functionality and to demonstrating the utility of the Ice Profiler's multi-target ranging and profiling capabilities for both conventional draft measurements and for clarifying more complicated measurement situations such as those previously encountered [2-4] with the more limited capabilities of the IPS4 profiling instrument.

\section{B. Ice Conditions in Winter 2007-2008}

The usual ice season in Northumberland Strait extends from approximately Jan. 1 to late March. During the 2007-

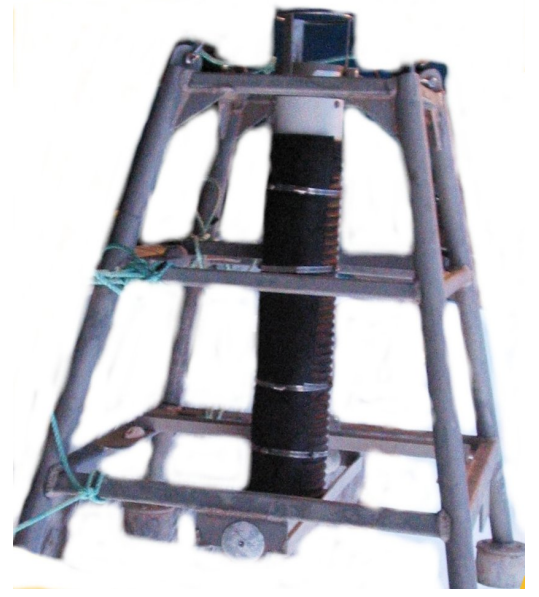

Figure 2. IPS5 upward looking sonar on mooring frame.

2008 winter, new and young ice first appeared at the site on Dec. 20 and persisted until ice clearance began in late March. The clearance process continued April 16. The resulting extended ice season, lasting about 2 weeks longer than normal, allowed for collection of much larger quantities of acoustic range and profile data relative to the ice season of 2006-2007 discussed in [1] which was 2-3 weeks shorter than normal. Even though a complete ice cover was in place in late December, changing weather patterns in mid-January produced partial ice clearing in Northumberland Strait at that time and, again, briefly in the last week of January.

\section{DATA PROCESSING AND ANALYSIS}

Reviews of the data sets were confined to two specific time periods selected to be most suitable for evaluating instrument performance in, alternatively, gathering data on wave statistics in open water periods and in characterizing the properties of ice in the water column and on or near the water surface, near ice infested conditions. The periods selected for these purposes, December 12-14, 2007and January 29 - February 4, 2008, respectively, provided representative open water and mixed ice/open conditions (with occasional patches of wave-in ice activity) suitable for realistic evaluations.

Processing of the Ice Profiler data was carried out using special purpose software developed by the manufacturer including the ASL Ice Profiling Processing Toolbox $(\mathcal{C}$ in Matlab( $\odot$ is used to process and analyse the acoustic range and ice draft data [6] while ASL's ProfileView(C) software allowed display and analysis of the full water column profile backscattering data sets. Barometric pressure data were obtained from the Environment Canada weather station at nearby Summerside PEI, to remove the contributions of atmospheric pressure on the water level measurements made with the Ice Profiler's onboard Paroscientific Digiquartz pressure sensor. Ice drafts were 
computed as the difference between water levels and acoustic ranges, after correction for the measured instrument tilt, to the underside of the sea-ice.

\section{RESULTS}

\section{A. Wave Statistics}

A new feature of the upgraded IPS5 Ice Profile was its "wave measurement" mode in which the instrument samples acoustic returns at $2 \mathrm{~Hz}$ during "bursts". The time duration of the burst sampling and the time between bursts is user selectable. The instrument continues to sample for acoustic returns from sea-ice at a user selectable ping rate on a continuous basis both during the wave burst measurements and in the interval between wave bursts. The instrument can be pre-programmed to collect data in up to 12 different sampling schemes, comprised of distinct measurement phases, with a start and stop time/date specified for each data collection phase. For the first phase in the present data record, the wave mode of data collection was used for burst sampling of acoustic range measurements at $2 \mathrm{~Hz}$ for 2048 samples (17.07 minutes) once each hour along with the collection of "ice" acoustic return samples once every 10 seconds.

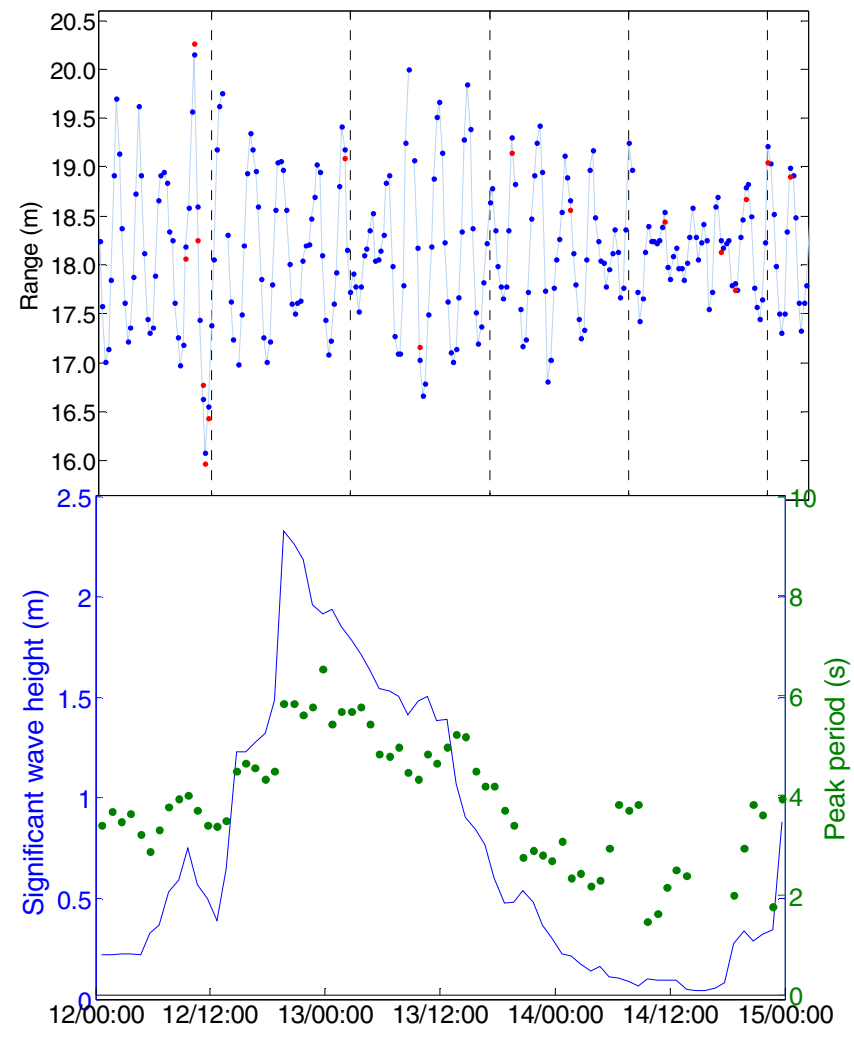

Figure 3: (upper) a one minute segment of $2 \mathrm{~Hz}$ acoustic range measurements of waves on Dec. 12

(lower) the computed significant wave height and peak period for the hourly acoustic wave data, Dec. 12-14, 2007.

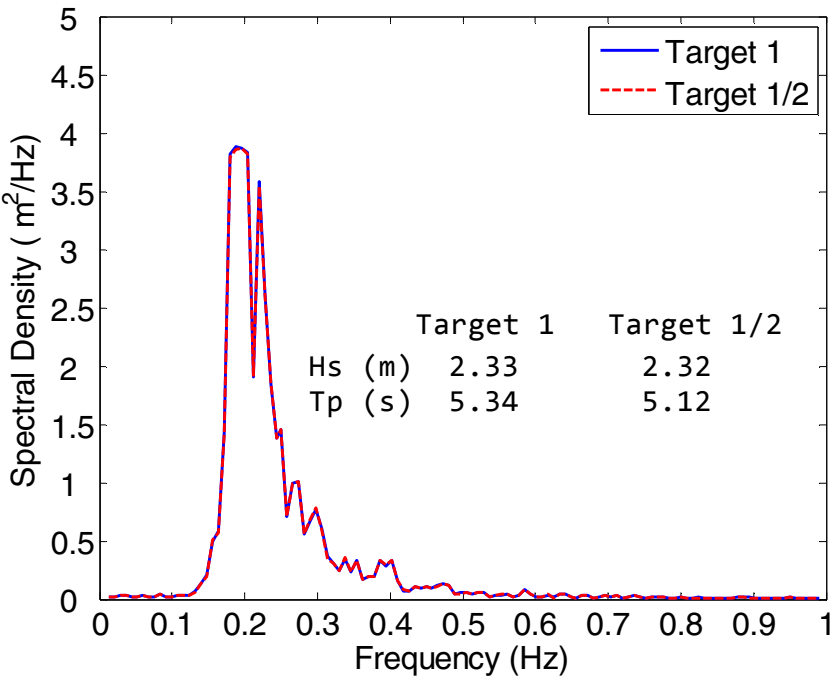

Figure 4: The wave spectra computed for the hourly wave burst data on Dec. 12 with the largest waves, computed with and without replacement of target 1 with target 2 when available.

A three day segment of the wave data, from Dec. 12-14, 2007, was selected for detailed analysis. In this time period, approximately one week prior to ice formation, large waves were present in Northumberland Strait under the influence of strong northwesterly winds from the with speeds of up to 25 knots. From the hourly bursts of range data (as shown in Figure $3 \mathrm{a}$ for a one-minute segment of the data), wave spectra were computed and used to provide values for the significant wave height, $\mathrm{Hs}$ and peak period, $\mathrm{Tp}$, wave parameters as displayed in Fig. $3 \mathrm{~b}$.

The multiple $(\leq 5)$ target feature of the instrument firmware allowed more than one acoustic target range to be realized in each ping. For wave measurements, sub-surface bubbles associated with white-capping represent potential targets additional to the water/air interface. For the Dec. 12-14 period, the largest number of targets measured never exceeded 2 and the percentage of wave acoustic pings having multiple targets instead of 1 was limited to $3 \%$ or less. In the short segment of acoustic ranges (Fig. 3a), the target 2 ranges are shown as red symbols while the first targets ranges are shown in blue. The bursts having the largest number of two target occurrences were associated with the largest wave heights. Usage of exclusively target 1 acoustic ranges, or target 2 plus target 1 ranges (when only one target was measured) was compared through computation of the wave spectra with these two different target sources. The wave spectra results and the derived wave parameters proved to be virtually identical as shown in Fig. 4. This comparison indicates that the acoustically derived wave measurements were very robust and that the Ice Profiler provides reliable wave measurements through the fall, winter and early spring seasons when occurrences of sea ice would preclude the use of surface wave buoys. 


\section{B. Ice characterization}

Initial analyses of the obtained results can be most easily based upon identified "target" data similar to that available from earlier, IPS4-based, studies and in the 2006-2007 IPS5 program [1]. In this case, however, the retention of data on up to 5 individual targets in each individual ping provided new information almost immediately relevant to ice characterization. As previously, the selection criteria identified targets with that portion of the returns from each individual ping which showed the exceedence of a minimum threshold return signal amplitude of 10,000 counts for a duration at least as large as a user-selected "persistence" time. Now, however, such data were stored and ranked by persistence for up to 5 such targets.

A plot of the first three of these targets in Fig. 5 as recorded during a 48 hour Jan. 29-30 period illustrates many of the features of the 2007-2008 data sets relevant to characterization of the ice cover environment. The Figure includes a plot of the corresponding time series of the approximate ranges associated with water levels (as derived from the hydrostatic and atmospheric pressure data) and, in a time interval roughly centred on 0600 , Jan. 29, a period of open water showing significant wave activity. Almost completely throughout the displayed record one also notes the presence of the three features previously found [1] in the
2006-2007 data sets: 1) semi-diurnal and diurnal variations in range corresponding to tidally varying open water or thin ice surfaces; 2) more irregular, somewhat closer-in returns consistent with scattering from thicker, rough, ice surface which extend downward no more than several meters from the approximate water surface; and 3) equivalently variable returns associated with targets 8 to $16 \mathrm{~m}$ below water surface. The latter targets were, as in 2006-2007, believed to be associated with turbulently mixed ice particles periodically generated by ice interactions with an upstream bridge pier. In this case, however, the previously observed limitations on the appearances of such particles to periods of falling tide was found to have been relaxed and deep targets were occasionally (see Fig. 5) detected, in generally lesser numbers at times close to tidal minima.

Use of first targets, in conjunction with an amplitude threshold again was found to provide a credible estimate of ranges to the rough and thin ice surfaces suitable for conversion to draft time series through the computed water levels derived from the hydrostatic and atmospheric pressure data (Fig. 6).

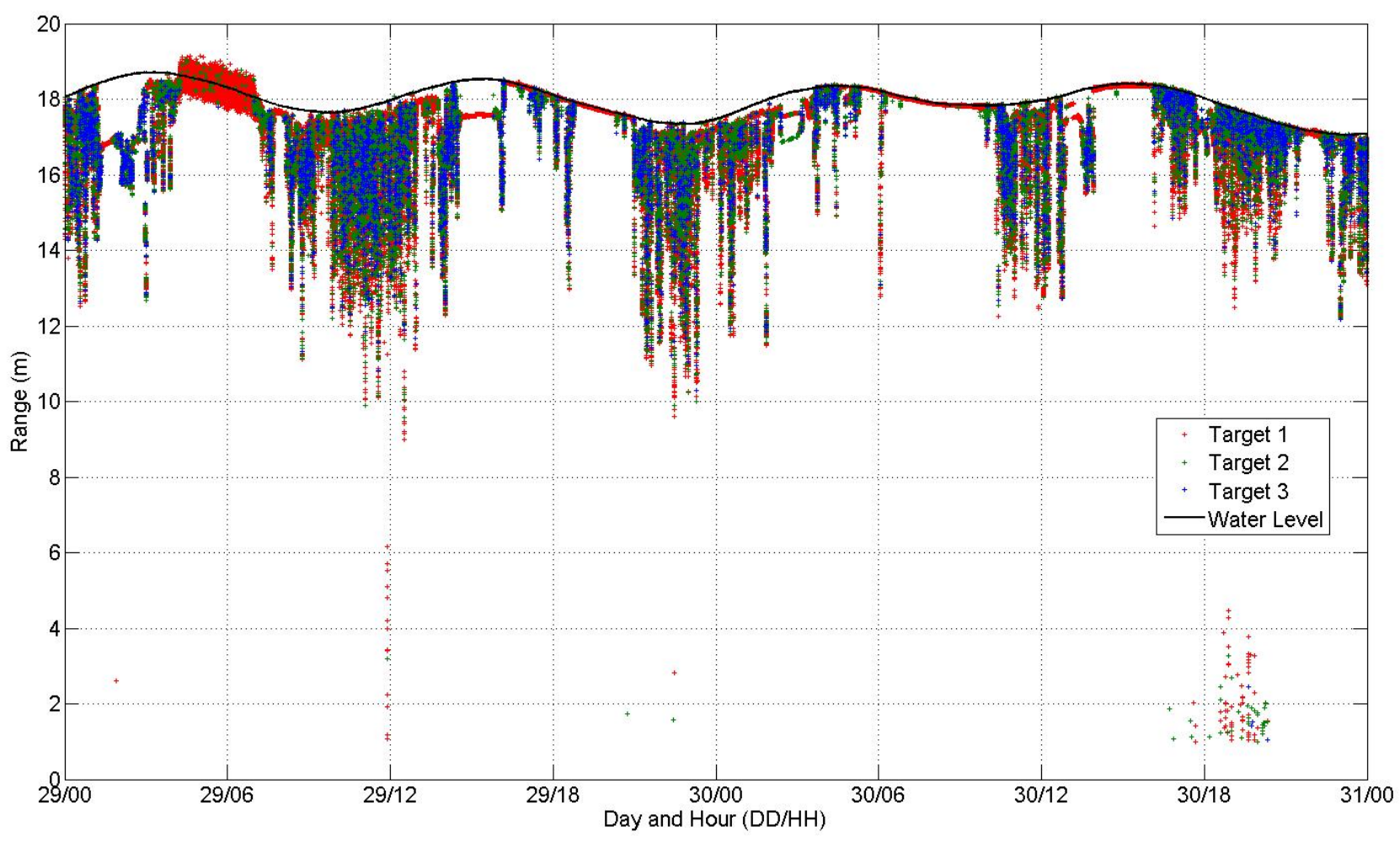

Figure 5. The acoustic ranges measured from Jan. 29 -30, 2008 inclusive, for the first three targets available from each ping. Also shown is the computed water level, after correction for atmospheric pressure, as measured by the Ice Profiler instrument. 


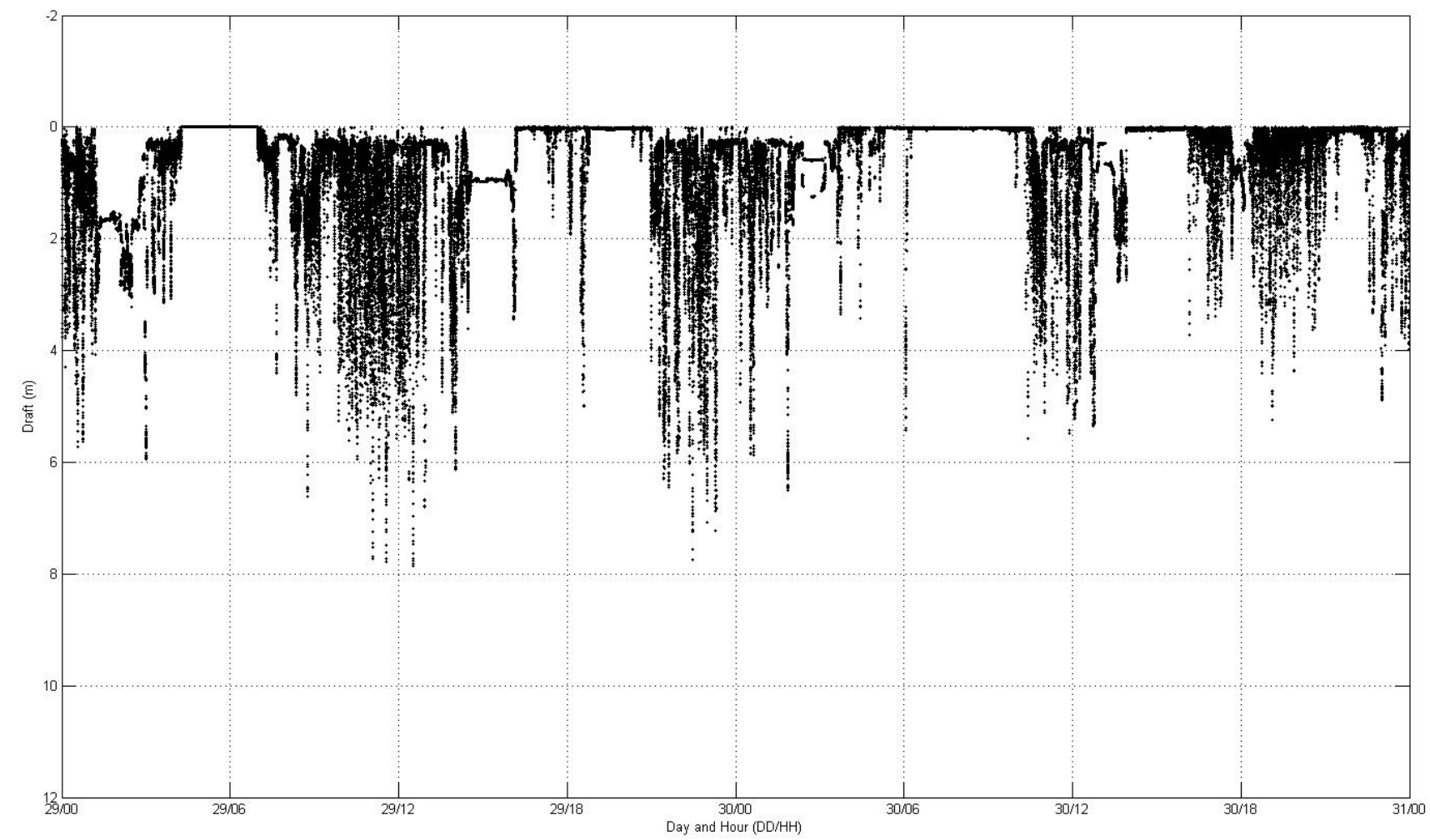

Figure 6. The computed ice drafts for January 29-30, 2008 as computed from the water level measurements less the measured values of acoustic range, at one second sampling intervals. Notice the occurrences of three distinct ice types: (a) open water and/or very thin ice, (b) episodes of comparatively flat level ice and (c) the heavily deformed ice keel features extending to depths of up to $8 \mathrm{~m}$.

TABLE 1

THE RELATIVE DISTRIBUTION OF MAXIMUM AMPLITUDES FOR VARIOUS ICE DRAFT CATEGORIES, EXPRESSED AS THE PERCENTAGE OF ALL TARGET AMPLITUDES AVAILABLE FOR EACH OF THE ICE DRAFT CATEGORIES.

\begin{tabular}{|c|c|c|c|c|c|c|c|}
\hline & \multicolumn{7}{|c|}{ Maximum Amplitude (counts) } \\
\hline & \multirow{2}{*}{$\begin{array}{c}10000 \\
\text { to } \\
20000\end{array}$} & \multirow{2}{*}{$\begin{array}{c}20000 \\
\text { to } \\
30000\end{array}$} & \multirow{2}{*}{$\begin{array}{c}30000 \\
\text { to } \\
40000\end{array}$} & \multirow{2}{*}{$\begin{array}{l}40000 \\
\text { to } \\
50000\end{array}$} & \multirow{2}{*}{$\begin{array}{l}50000 \\
\text { to } \\
65535\end{array}$} & \multirow{2}{*}{$\begin{array}{c}65535 \\
\text { to } \\
65536\end{array}$} & \multirow{2}{*}{$\begin{array}{l}\text { Row } \\
\text { Total } \\
\text { (\%) }\end{array}$} \\
\hline $\operatorname{Draft}(\mathrm{m})$ & & & & & & & \\
\hline 0.0 to 0.1 & $0.6 \%$ & $1.0 \%$ & $1.0 \%$ & $1.0 \%$ & $1.6 \%$ & $94.9 \%$ & 40.96 \\
\hline 0.1 to 0.2 & $11.4 \%$ & $19.3 \%$ & $16.9 \%$ & $12.6 \%$ & $12.8 \%$ & $27.0 \%$ & 3.08 \\
\hline 0.2 to 0.3 & $13.7 \%$ & $13.3 \%$ & $12.3 \%$ & $9.1 \%$ & $10.1 \%$ & $41.5 \%$ & 9.46 \\
\hline 0.3 to 0.5 & $14.1 \%$ & $17.5 \%$ & $15.3 \%$ & $11.5 \%$ & $11.8 \%$ & $29.9 \%$ & 10.91 \\
\hline 0.5 to 0.7 & $35.2 \%$ & $18.7 \%$ & $15.0 \%$ & $9.6 \%$ & $8.0 \%$ & $13.4 \%$ & 6.26 \\
\hline 0.7 to 1.0 & $26.4 \%$ & $32.8 \%$ & $22.9 \%$ & $7.2 \%$ & $5.3 \%$ & $5.3 \%$ & 7.58 \\
\hline 1.0 to 1.5 & $25.0 \%$ & $31.7 \%$ & $20.4 \%$ & $10.9 \%$ & $7.5 \%$ & $4.5 \%$ & 6.16 \\
\hline 1.5 to 2.0 & $21.7 \%$ & $31.3 \%$ & $25.7 \%$ & $13.6 \%$ & $5.7 \%$ & $2.0 \%$ & 6.26 \\
\hline 2.0 to 2.5 & $25.7 \%$ & $34.0 \%$ & $21.7 \%$ & $10.2 \%$ & $6.5 \%$ & $1.7 \%$ & 2.99 \\
\hline 2.5 to 3.0 & $21.9 \%$ & $34.1 \%$ & $22.3 \%$ & $12.1 \%$ & $7.0 \%$ & $2.7 \%$ & 2.46 \\
\hline 3.0 to 4.0 & $25.4 \%$ & $32.7 \%$ & $22.0 \%$ & $10.8 \%$ & $6.5 \%$ & $2.6 \%$ & 2.27 \\
\hline 4.0 to 5.0 & $25.9 \%$ & $33.1 \%$ & $21.0 \%$ & $11.5 \%$ & $5.7 \%$ & $2.8 \%$ & 1.02 \\
\hline 5.0 to 8.0 & $22.4 \%$ & $31.1 \%$ & $23.7 \%$ & $10.1 \%$ & $8.2 \%$ & $4.5 \%$ & 0.58 \\
\hline Column Total (\%) & 12.81 & 14.84 & 11.35 & 6.60 & 5.63 & 48.78 & \\
\hline
\end{tabular}

Conversion of individual target range values into drafts also produced very interesting results relevant to prospects for using target amplitude data for distinguishing between ice and open water. These results, presented in Table 1 show the percentages of recorded amplitude values from the period Jan 29-30 in each of several amplitude ranges as a function of the drafts associated with the "first" target on each ping. The high $(94.9 \%)$ percentage of saturated $(65,535)$ returns for targets with "drafts" of $0-10 \mathrm{~cm}$ is consistent with expectations of extremely strong scattering at or near the air/water interface [7]. The shift of the predominant returns to lower amplitudes at greater depths reflects the lessened mismatch in acoustic impedance at the ice/water surface. This distinction between returns from ocean surface and ice targets has been made possible by the 16-bit resolution of the Ice Profiler which allowed the use of lower system gains and consequent detection of nonsaturated returns from ice targets.

Finally, it is of interest to return to Fig. 5 to examine the so far neglected first type of the three identified "ice features", namely the relatively rare (in Fig. 5, at least) stretches of open water or thin ice which are devoid of the generally more irregular and deeper returns associated with the other identified target types. This first type of return can be seen to have occurred in distinct intervals more or less confined to periods an hour or two in duration coinciding with or immediately preceding tidal maxima and minima. Such periods are characterized by low or negligible current speeds or "slack water". The third category of targets, the 
deep water column targets, appears to be totally absent in these intervals and, in most cases, observed target ranges tend to be nearly constant, consistent with the presence of a relatively immobile ice cover, usually with a draft of $1 \mathrm{~m}$ or less (see the interval centred on 15:00, Jan. 29), sitting over the Ice Profiler monitoring site. Yet other intervals were noted, mostly in the mid-winter late January-February months, in which returns were often received consistently and simultaneously (i.e. in the same ping) from multiple targets.

Examples of relatively thin and uniform thickness ice are evident in Fig. 5 at times, centred on approximately 0230 and 1330, January 30, associated with approaches to tidal maxima. In the study area, the flows at these times corresponded to the slowing of an ebbing tide when the water flows were directed toward and not away from the bridge pier sources of ice fragments. The anomalous returns were not evident in the alternative type of slack water interval, associated with the approach to a tidal minimum and a prevailing flow from the bridge pier toward the IPS5 instrument. It should be noted that similar multiple returns in the ebbing flow cycle were also present in the 2006-2007 "first target" observations [1] but were not noted at the time. It is possible that the more consistent association of the presence of deep water column target returns with the flooding cycle flow in the earlier year may be indicative of the fact that the latter effect may have been associated with the greater presence in the flooding cycle of less buoyant, very small, particle targets which were less detectable in 2007-2008 because of the lower utilized gain levels. Such particles could subsequently form larger, more buoyant aggregates which are detected closer to the ice cover during the following ebb cycle slack water period.

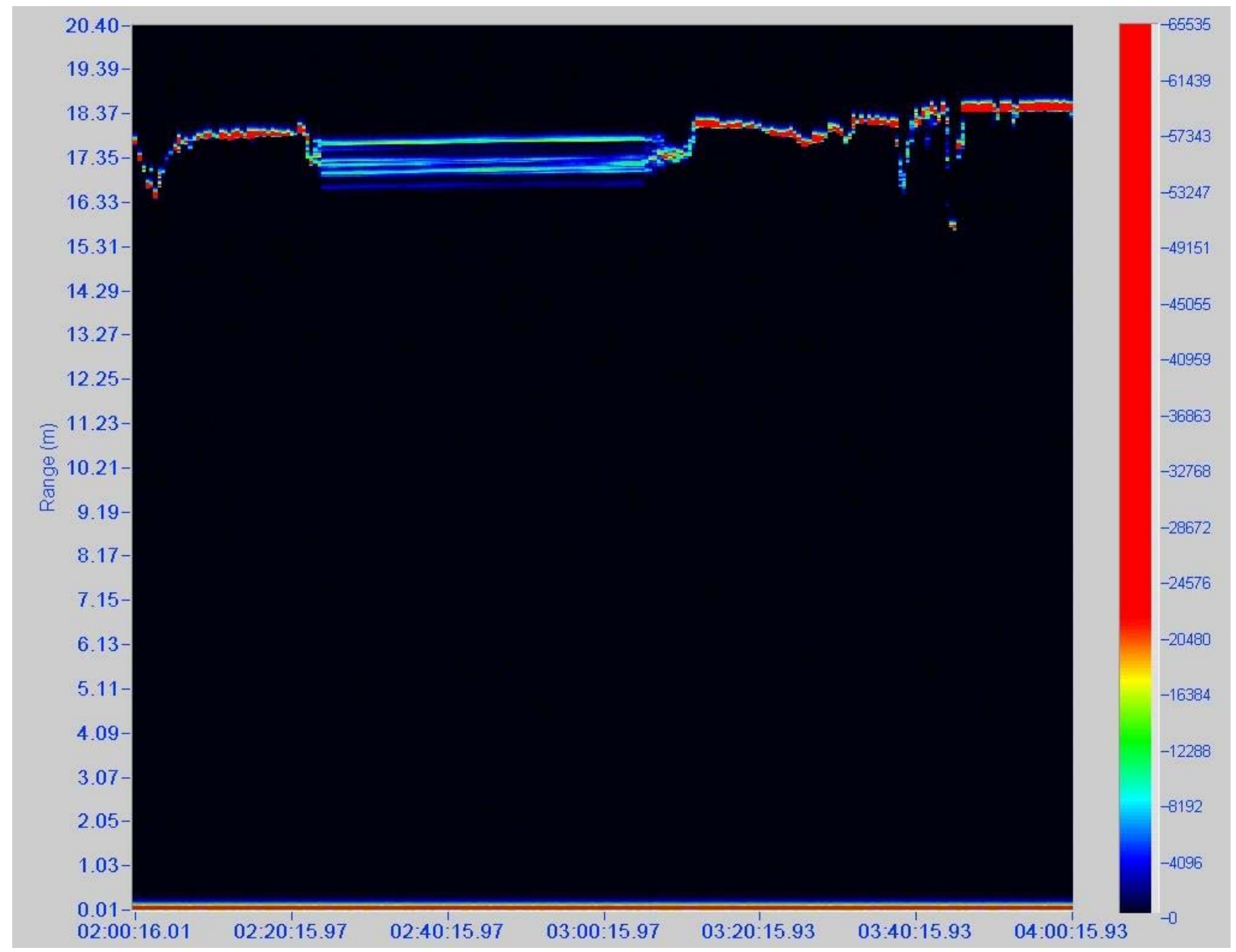

Figure 7. The measured backscattering amplitude over the full water column at 30 second intervals for the period 0200 to 0400 on January $30,2008$. 
The full water column profiling capability of the IPS5 provided a more detailed look at the anomalous returns (Fig. 7) which shows the structure of the returns during the 0230 , Jan. 30 interval. At any given time, at least 4 distinct returns could be distinguished, with 5 returns being present for shorter periods. The stability of the returns is particularly impressive given that the results depict range profiles as recorded from single pings emitted at 30 second intervals. As indicated by the colour code, the strongest returns came from the largest fixed range target which (see Fig. 6) corresponded to a draft of, roughly, $0.6 \mathrm{~m}$. Other, sometimes almost equally intense, targets appeared at depths 0.5 to $0.75 \mathrm{~m}$ deeper in the water column with an additional much weaker target also being present approximately $1 \mathrm{~m}$ below the strongest target. Although further analyses, preferably in conjunction with modeled and/or measured current speed estimates, are required for full explication, we believe the highest range target probably represents the undersurface of a relatively flat floe moving extremely slowly over the monitoring site. Acoustic returns from this undersurface are being detected though distinct layers of relatively acoustically transparent ice comprised of the ice particles and fragments which extend much deeper into the water column during other portions of the tidal cycle. The slight drift of the ice during the anomalous period produces fluctuations in the strengths of the returns from the edges of these distinct layers with concomitant and opposing effects on the strength of returns from the uppermost, $0.6 \mathrm{~m}$ draft, ice target.

In our conceptual model, the lower target layers form when ice particles/fragments rise in the water column due to the reduced turbulence characteristic of the slack water period. Obviously, several puzzles remain in this picture including the mechanisms underlying the distinct layering of such ice and the apparent confinement of such effects to the times of slack water following ebb flow periods. It is to be hoped that additional analyses and further, more complete, field studies will be able to addresses these issues. A shortening of the time interval between successive profiling pings would be particularly helpful in this regard.

More generally, the results obtained from the multiple target and profiling efforts appear to hold promise for fuller characterization of a marine ice cover and its composition in terms of "harder" and "softer" ice components. The postulated apparent acoustic penetrability of some of the latter, even at the relatively high $420 \mathrm{kHz}$ frequency of the utilized IPS5 Ice Profiler unit would appear to be encouraging for further efforts toward classifying ice types in, at least, the lower portions of marine ice covers.

\section{CONCLUSIONS}

A second year of IPS5 Profiler measurements in Northumberland Strait has demonstrated important advantages offered by the instrument's 16-bit resolution and improved firmware, including successful operation in an ocean wave measurement mode. The upgraded features included lowered power levels and opened new possibilities for rapid data interpretation and processing through detection of multiple ice targets, most of which are associated with unsaturated acoustic returns. The results ,obtained on the Northumberland Strait ice cover, were nominally similar to those obtained in the preceding 2006-2007 study but, primarily because of new capabilities for measurements at lower power levels, yielded new insights on the composition of the lower ice cover and its connections with the tidal flow cycle.

\section{ACKNOWLEDGMENTS}

The authors thank Confederation Bridge Ltd. for accommodating and or facilitating this effort. We also thank our ASL colleagues who contributed to this paper: the ASL IPS5 development team including Rene Chave, Murray Clarke and Matt Stone. We also thank our colleagues in PWGSC, Strait Crossing Inc., and the University of Calgary for their ongoing contributions to the ice research studies conducted at the Confederation Bridge.

\section{REFERENCES}

[1] D.B. Fissel, J.R. Marko, E. Ross, V. Lee, R.A.J. Chave and J. Egan. "Improvements in Upward Looking Sonar-based Sea-Ice Measurements: A Case Study for 2007 Ice Features in Northumberland Strait, Canada". in Proceedings, IEEE/MTS Oceans 2008 Conference, Vancouver BC Canada, Oct. 1-4, 2007. Paper 0933957-35-1.

[2] H.B. Hayden, D.J. Belliveau and S.J. Prinsenberg. "Ice Drift and Draft from Moorings at the Confederation Bridge January - March 2000. Can. Data Rep. Hydrogr. Ocean Sci., vol. 158. Canada Dept. of Fisheries and Oceans, iv +186 p., 2002

[3] H.B. Hayden, D.J. Belliveau and S.J. Prinsenberg. "Ice Drift and Draft from Moorings at the Confederation Bridge January - March 2002. Can. Data Rep. Hydrogr. Ocean Sci., vol. 163. Canada Dept. of Fisheries and Oceans, iv +209 p., 2003.

[4] D. J. Belliveau, H. Hayden, S. Prinsenberg. "Ice Drift and Draft Measurements from Moorings at the Confederation Bridge," in Proceedings, $16^{\text {th }}$ Int. Conference on Ports and Ocean Engineering under Arctic Conditions, Ottawa Canada Aug. 12-17, 2001., pp. 349358,2001

[5] K.M. Obert and T.G. Brown. "First-Year Ice Ridge Keels in Northumberland Strait " in Proceedings, ICETECH 2008, International Conference and Exhibition on Performance of Ships and Structures in Ice, Banff Canada, July 20-23, 2008., ISBN 978-09780896-1-0.

[6] D. Billenness, D.Fissel, E. Ross, D. Lemon, and K. Borg. ASL Ice Profiler Processing Toolbox User's Guide. Sidney, BC: ASL Environmental Sciences Inc., 2007.

[7] H. Melling. "Sound scattering from sea ice: Aspects relevant to icedraft profiling by sonar." Journal of Atmospheric and Oceanic Technology. 15(4):1023-1034.D., 1998. 